\title{
INFORMATION SECURITY EDUCATION SYSTEM IN SECONDARY SCHOOL AND ASSESSMENT OF THE LEVEL OF ANXIETY OF SCHOOLCHILDREN
}

\author{
Mikhail I. Bocharov ${ }^{1}$, Irina V. Simonova ${ }^{2}$, Tatyana I. Bocharova ${ }^{3}$ and Anna Y. Zaika ${ }^{4}$ \\ ${ }^{1}$ Moscow City University, Vtoroy Selskohoziajstvenny proezd, 4, Moscow, 129226, Russia \\ ${ }^{2}$ Herzen State Pedagogical University of Russia, Moika River, 48, St. Petersburg, 191186, Russia \\ ${ }^{3}$ Moscow Technical University of Communications and Informatics, Aviamotornaya Street, 8A, Moscow, 111024, Russia \\ ${ }^{4}$ National University of Kyiv-Mohyla Academy, 2 Skovoroda St., Kyiv, 04655, Ukraine
}

\begin{abstract}
The analysis of the results of scientific research has revealed the necessity to track the level of anxiety of a student while studying aspects of information security in a particular subject area. And in accordance with the results, it was necessary to justify the choice of methods for management and content of information security training in order to minimize the negative impact on the psychological state of a child of middle school age. The purpose of the research is to determine the impact of educational elements from a specific subject area related to information security guaranteeing on the level of anxiety of secondary schools students.

The authors identified the need to assess the level of anxiety of students while studying aspects of information security in a particular subject area and proposed tools for tracking the level of anxiety. In the middle school, during the formation of a comprehensive idea of professional activities in the field of information security, especially at the pre-profile stage, an approach that forms the basis for the formation of the content of information security training is substantiated. It combines the knowledge from a wide range of different sciences for teaching secondary school students. The study shows that the level of situational anxiety of secondary school students while studying aspects of information security in a particular subject area can increase due to the natural reaction of the body, adapting to new potential threats for it. It was experimentally established that the level of personal anxiety as a result of assimilation of new knowledge about information security did not change both before studying the educational elements of information security in a particular subject area, and after studying them.
\end{abstract}

\section{KEYWORDS}

Digital Education, Information Security of Students, the Conceptual Apparatus of Information Security, Sources of Information Threats, Information Security Training, the Level of Anxiety of Adolescents

\section{INTRODUCTION}

During the transition from elementary school to secondary school, the level of independence of the student and, accordingly, his/her autonomy in decision-making process in the situation of information threat, which implies the choice of a particular action, increases. In elementary school, the child is under the supervision of adults to a greater extent, therefore, while teaching information security issues in elementary school (Bocharov M., 2019), one can limit oneself to a description of the information security problem itself and a certain set of typical situations in which a primary school student may be without the immediate proximity of his/her guardians. Such situations require the "inclusion" of protective mechanisms. This approach is justified at the elementary school stage, when the student is under the close supervision of parents and teachers, and the set of situations that a younger student may encounter is limited. However, with an increase in the degree of independence of the child during the transition to secondary school, the number of such "typical situations" tends to increase sharply. More effective in secondary school is an approach based on the use of a conceptual apparatus, which allows to highlight common points in almost any real situation and explore them using well-known concepts. 
More and more researchers and practitioners are paying attention to the need for active development of the problems of information and psychological security of the individual, society and the state. This is due to the fact that without the solution of these problems it is impossible to further sustainable social development and ensure the security of the individual, society and the state in the political, economic, social, spiritual, military and other fields.

The place of information security in the system of modern scientific knowledge is determined mainly by the fact that information security is a branch of a computer science. Methods and tools of informatics can be general, fundamental, and applied, taking into account the specifics of pedagogy, medicine or law. Hence, it is proposed to subdivide computer science into theoretical (fundamental) and applied. Applied informatics includes pedagogical informatics, medical informatics, legal informatics, etc. Therefore, information security is present both in theoretical (fundamental) computer science and in applied science, i.e. in legal, medical, pedagogical informatics, etc. (Abissova M., 2006).

\section{COMPONENTS OF INFORMATION SECURITY TRAINING IN SECONDARY SCHOOLS}

In the middle school, during the formation of a comprehensive idea of professional activity in the field of information security, especially at the pre-specialized preparation stage, it is necessary to take into account the integrative principles that form the basis for the formation of the content of information security training, combining knowledge from a wide range of different sciences. So, the basis for the development of the content of vocational training for information security of education system employees T.L. Partyka and I.I. Popov put the following principles (Partyka T., 2007): universality, integration, the integrity of the scientific picture of the world, fundamental nature, professionalism, variability. (Chou H. et al, 2016).

The middle level of the school is the main link for the formation of key concepts in the field of information security. These concepts are grouped by type of information security. The information security system includes the following types of security: organizational support, psychological support, legal support, information support, linguistic support, social and ethical support, spiritual and moral support, software, hardware, math support, engineering and technical support.

Let us define the subjects (educational areas), the content of which can highlight the educational elements related to the field of information security in the Russian federal basic curriculum of basic general education and in the system of additional education of schoolchildren. Within each subject, we define a key concept that reflects to a large extent the substantial part of information security elements related to this subject. Let us compare the types of information security with the content for each subject selected for studying the basics of information security. As a result, we obtain the following correspondences between basic subjects, substantive elements, and types of information security guaranteeing, presented in Table 1.

Table 1. Correspondence between basic subjects, substantive elements and types of information security

\begin{tabular}{l|l|l}
\hline $\begin{array}{c}\text { Basic subjects in basic general } \\
\text { education for teaching the basics } \\
\text { of information security }\end{array}$ & $\begin{array}{c}\text { Content elements of } \\
\text { teaching the basics of } \\
\text { information security }\end{array}$ & Types of information security support \\
\hline Informatics & Software & Software \\
\hline Math & Cryptographic & Mathematical \\
\hline Physics & Physical & Hardware \\
\hline Social Studies & Social, legal & Psychological, socio-ethical, legal \\
\hline General History & Historical, factual & Socio-ethical \\
\hline Life Safety Fundamentals & Organizational & Organizational \\
\hline Literature & Spiritual, moral, ethical & Linguistic, socio-ethical, spiritual, moral \\
\hline Foreign language & Communicative, ethical & Organizational, linguistic \\
\hline Art & Spiritual, moral, ethical & Social and ethical, spiritual, moral \\
\hline The subject area "Technology" & Hardware and technical & Hardware \\
\hline $\begin{array}{l}\text { The subject area "Fundamentals } \\
\text { of spiritual and moral culture" }\end{array}$ & Spiritual, moral, ethical & Spiritual and moral \\
\hline
\end{tabular}


Key states on the role of intersubject connections in the formation of concepts in students, formulated by A.V. Usova, can be applied to the formation of basic concepts in the field of information security. Interdisciplinary connection is a reflection of the relationship between the sciences, the foundations of which are studied at school, in the content of the educational material, in its structure and teaching methods (Usova A., 1986).

\section{INTEGRATIVE MODEL OF TEACHING INFORMATION SECURITY TO STUDENTS OF MIDDLE SCHOOL AGE}

In our opinion, an effective way to improve the quality of understanding concepts in the field of information security by schoolchildren is to solve problems of an interdisciplinary nature. According to A. V. Usova, the solution of such problems requires students to establish links between concepts formed in the study of various academic subjects, which plays an important role in the formation of students' natural science picture of the world (Usova A., 1986). An effective method for solving such problems is the method of (creative) projects.

The consistent formation of independent critical thinking in schoolchildren in the process of all educational subjects can be facilitated by the introduction of a media education course in school curricula (Larsson K., 2017). Media education is a subject area that studies the specific language of various media, primarily television, radio, the press, and the Internet.

M.A. Abissova in the field of information security training distinguishes three levels depending on how much material is provided for training information security according to state educational standards of higher professional education: 1) future specialists in the field of information security and other areas of computer science (several general professional and special disciplines); 2) future specialists not in the field of computer science (one general professional discipline "Information Security" for some specialties); 3) students of humanitarian and socio-economic specialties (section of basic informatics - a general discipline called "Informatics" or "Informatics and mathematics"). All students study a small section in the basic course "Jurisprudence" (Abissova M., 2006).

Based on this, certain priorities can be identified in the content of pre-specialized training of schoolchildren in information security in one or another educational area.

In relation to natural sciences (areas), the content of such training will be determined by the theoretical foundations of the security of information systems. In technical specialties (areas) issues related to protected information technologies will be disclosed. In humanitarian specialties (directions), attention should be paid to studying the issues of combating computer crimes.

The ideas received by students during the study of various school subjects about certain aspects of information security should be generalized and systematized for subsequent career guidance and the implementation of pre-specialized training. This can be done on the basis of the organization of intersubject communications and the involvement of students in project activities in the manner presented in Figure 1 as an integrative model for teaching information security to students of middle school age.

A feature of teaching schoolchildren at this age stage compared to primary school is the increased influence of the Internet and network communities both in educational activities and in the student's personal, social extracurricular life (Chou H. et al, 2017).

The following statements can be identified as sources of threats to the information security of students using the Internet in the educational process:

1. The nature of the incoming information and how to set the computer according to the content of the incoming information from the Internet is known to a small number of parents of secondary school students, which indicates the absence of parental censorship.

2. Minor Internet users are aware of many ways to overcome locks from the reception of unwanted information.

3. Many parents have superficial ideas about the psychological problems of adolescents associated with the uncontrolled use of Internet resources, do not give their children an idea of the problem of maintaining privacy, do not use any means to filter negative information (Lau W. et al, 2016).

4. Juvenile Internet users are not aware of the legal rules regarding their rights and the principle of "democracy" of the Network. 
5. Due to the physical and mental characteristics of childhood and the lack of life experience and life support for a child, in comparison with adults, it is much more difficult to defend one's own rights. Excessive enthusiasm for "virtual reality" leads to a decrease in the experience of real interaction.

6. Most students while working on the Web consider the information interaction on the Web anonymous (actions, messages to chats and letters).

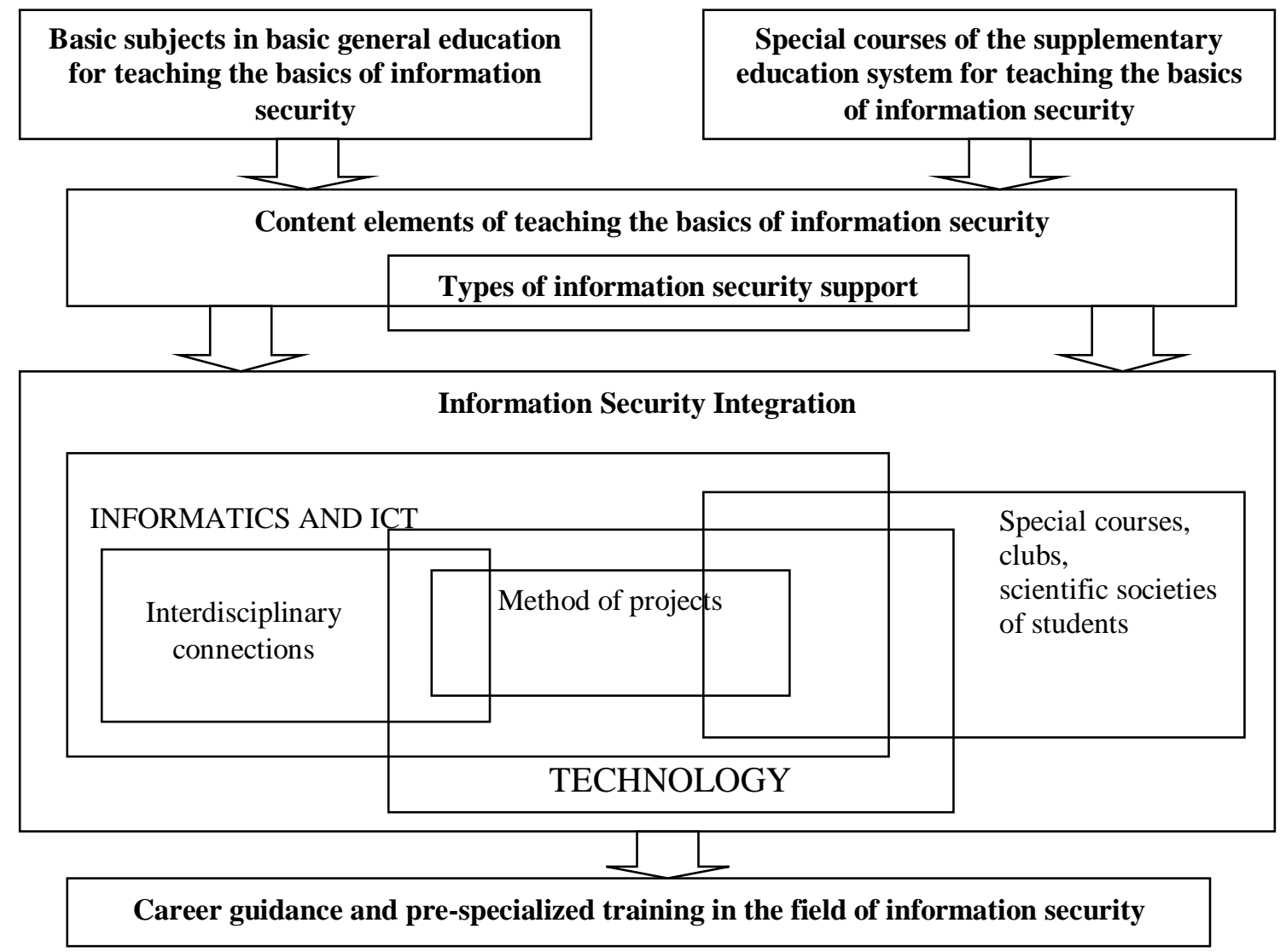

Figure 1. Integrative model of teaching information security to secondary school students

Sources of information security threats on the Internet can be such negative social manifestations as the following (Dzhonson S., 2006.): porn industry, paedophilia, crime and terrorism, cyberbullying, invasion of privacy.

The porn industry is a source of pornography and obscene information on the Internet. There are hundreds of thousands of Web sites containing information that may be considered obscene.

Pedophiles use the Internet to track down children. Pedophile is an adult who has a sexual desire for children. Pedophiles use the Internet to organize the distribution of child porn photographs, as well as to select specific children and establish contacts with them.

Crime and terrorism. Not only children can easily find pornography, but they can also easily get information about committing crimes, such as making bombs, making drugs and stealing money, making fake IDs and etc (Thompson N. et al, 2017).

Cyberbullying - attacks through electronic devices. This can be defamation on Web sites, threats made through mail or mobile phone. Cyberbullying is the equivalent of street bullying in the information society. It is necessary to closely monitor the child for signs of its manifestation (Plaza-de-la-Hoz J. et al, 2018). Signs of cyberbullying can be determined by observing the reaction of children when they receive instant messages on a computer or SMS to their cell phone. Other symptoms may include a refusal to go to school, a sudden drop in self-esteem, depression or a refusal to use a computer or mobile phone (Yhomee S. et al, 2012.

Invasion of privacy. The worldwide disadvantage of the Internet is the possibility of violating the privacy law, which can also endanger the privacy of the child when he uses the Internet. 
Through the Internet, an advertiser can obtain information about a child in three main ways: when they subscribe to free services on the Internet; when they participate in competitions and lotteries; when they launch a viral advertisement with a click of the mouse.

The collected information may include the following: personal information such as name, address, and phone number; software applications installed on computer; the websites you visit and the details of the forms you fill out on web pages; advertising that you click on the mouse; a list of all the files that you download; your data for accessing the Internet, including your IP address, user login and Internet password.

All of the above factors with particular acuteness raise the question of the need for a comprehensive study of the entire set of socio-psychological phenomena caused by the emergence of a new information-psychological environment in relation to: teaching students to identify threats to information security and counter them to reduce the consequences of mental, moral and physical influence; determining the place of information security in the future professional activities of schoolchildren.

\section{METHODS}

To assess the child's training in information security aspects in a particular subject area in the experimental and control classes, a conceptual level in the field of information security was determined before and after the experiment. Studies were conducted in schools of Moscow, the city of St. Petersburg, the city of Novokuznetsk.

So in the framework of the subject "Fundamentals of Spiritual and Moral Culture", an important aspect of information security was considered as "Network etiquette" - netiquette (from the English net "network" + French etiquette "etiquette") - neologism of the rules of behavior, communication on the Web, the traditions and cultures of the online community, which most people adhere to. After studying the topic "Network Etiquette" by students, statistically significant differences in the child's training in knowledge of information security concepts related to network etiquette are established.

During the experimental training, the level of anxiety of schoolchildren was assessed, while studying the aspects of information security in a particular subject area, measurements were performed twice: before training and after training. To determine the level of anxiety, the Spilberger Alert Scale methodology, also known as the State-Trait Anxiety Inventory (STAI) developed by Charles Donald Spielberger, was used. STAI was adapted into Russian by Yu. L. Khanin.

This questionnaire consists of 20 statements related to anxiety as a state (state of anxiety, reactive or situational anxiety) and 20 statements to define anxiety as a disposition, personality traits (anxiety property or personal anxiety). Each statement is evaluated on a four-point scale from 1 to 4 , after which, in accordance with the STAI scheme, the total result of the obtained values is calculated, based on which the level of anxiety is determined: 1) up to 30 points - a low degree of anxiety; 2) from 31 to 45 points - an average degree of anxiety; 3 ) from 46 points or more - a high degree of anxiety.

C.D. Spielberger generally understands anxiety as "Anxiety is characterized by subjective, consciously perceived sensations of threat and tension, accompanied or associated with the activation or arousal of the autonomic nervous system."

Personal anxiety as a personality trait, apparently, means a motive or acquired behavioral disposition, which obliges the individual to perceive a wide range of objectively safe circumstances as containing a threat, prompting him to react to them with states of anxiety, the intensity of which does not correspond to the magnitude of the real danger. The Spielberger Reactive and Personal Anxiety Scale is a complex technique that allows you to differentially measure anxiety both as a personal property and as a state.

Situational (reactive) anxiety is the state of a person at a given moment of time, which is characterized by subjectively experienced emotions: tension, anxiety, concern, nervousness in a given specific situation. This state arises as an emotional reaction to an extreme or stressful situation, it can be different in intensity and dynamic over time.

Using STAI, anxiety levels in interpersonal interaction were identified as indicators of the psychological state of schoolchildren before and after studying the information security aspect associated with network etiquette.

As a result of an experimental study, an analysis of typical mechanisms of psychological defense in children of secondary school age was made and the levels of anxiety were determined. 
Since schoolchildren were included in the educational process and other educational influences, in addition to the experiment, could affect their level of anxiety, for the experiment two independent groups of subjects were formed - the experimental and control groups, according to which the corresponding independent samples were obtained.

The homogeneity of the experimental and control groups was established prior to the experiment. Data on situational anxiety obtained before the experiment are presented in table 2. Data on personal anxiety obtained before the experiment are presented in table 3. Data on situational anxiety obtained after the experiment are presented in table 4. Data on personal anxiety after the experiment are presented in table 5.

To determine the change in the level of situational anxiety, let us compare the data obtained in table 2 with the data in table 4 . To determine the change and the level of personal anxiety, let us compare the data obtained in table 3 with the data in table 5.

Table 2. Pre-experiment situational anxiety data

\begin{tabular}{lcccc}
\hline & \multicolumn{3}{c}{ Experimental group } & Control group \\
\hline Level & Number of people & $\%$ & Number of people & $\%$ \\
\hline High & 19 & 30,65 & 14 & 21,54 \\
Average & 27 & 43,55 & 31 & 47,69 \\
Low & 16 & 25,81 & 20 & 30,77 \\
Total & 62 & 100,00 & 65 & 100 \\
\hline
\end{tabular}

Table 3. Personal anxiety data obtained before the experiment

\begin{tabular}{lclcl}
\hline \multicolumn{2}{c}{ Experimental group } & \multicolumn{3}{c}{ Control group } \\
\hline Level & Number of people & $\%$ & Number of people & $\%$ \\
\hline High & 15 & 24,19 & 18 & 27,69 \\
Average & 36 & 58,06 & 38 & 58,46 \\
Low & 11 & 17,74 & 9 & 13,85 \\
Total & 62 & 100,00 & 65 & 100 \\
\hline
\end{tabular}

Table 4. Post-experiment situational anxiety data

\begin{tabular}{lcccc}
\hline & \multicolumn{3}{c}{ Experimental group } & Control group \\
\hline Level & Number of people & $\%$ & Number of people & $\%$ \\
\hline High & 27 & 43,55 & 14 & 21,54 \\
Average & 26 & 41,94 & 29 & 44,62 \\
Low & 9 & 14,52 & 22 & 33,85 \\
Total & 62 & 100,00 & 65 & 100,00 \\
\hline
\end{tabular}

Table 5. Personal anxiety data obtained after the situational anxiety experiment

\begin{tabular}{lclcl}
\hline & \multicolumn{3}{c}{ Experimental group } & Control group \\
\hline Level & Number of people & $\%$ & Number of people & $\%$ \\
\hline High & 22 & 35,48 & 16 & 24,62 \\
Average & 32 & 51,61 & 34 & 52,31 \\
Low & 8 & 12,90 & 15 & 23,08 \\
Total & 62 & 100,00 & 65 & 100 \\
\hline
\end{tabular}

To identify significant differences in the level of anxiety for independent samples, the Pearson $\chi^{2}$ criterion was used. In this case, it was applied to three gradation levels of the studied feature. 
In our case, for three rows and two compared columns, two degrees of freedom are obtained (we determine the number of degrees of freedom by the formula: $f=$ (number of rows -1$) \times($ number of independent compared columns -1$)=(3-1) \times(2-1)=2)$, for which we select the tabular critical values $\chi 2 \mathrm{cr}$ $=9.210$ for $1 \%$ significance level and $\chi 2 \mathrm{cr}=5.991$ for $5 \%$ significance level and compare them with the obtained $\chi 2$ emp values in table 6 and table 7 .

Table 6. Comparison of the level of situational anxiety of students in the experimental and control groups before and after the experiment

\begin{tabular}{lc}
\hline & $\begin{array}{c}\text { The value of the uniformity } \\
\text { criterion } \chi^{2}\end{array}$ \\
\hline Comparison of the level of anxiety of students before the experiment & 1,407801684 \\
Comparison of the level of anxiety of students after the experiment & 9,671731181 \\
\hline
\end{tabular}

Table 7. Comparison of the level of personal anxiety of schoolchildren in the experimental and control groups before and after the experiment

\begin{tabular}{lc}
\hline Comparison of the level of anxiety of students before the experiment & $\begin{array}{c}\text { The value of the uniformity } \\
\text { criterion } \chi^{2}\end{array}$ \\
\hline Comparison of the level of anxiety of students after the experiment & 0,456169728 \\
3,069255771
\end{tabular}

\section{CONCLUSION}

In accordance with the developed model of the research, based on the results of the study of the section "Network etiquette" included in the subject area "Fundamentals of Spiritual and Moral Culture" by students, statistically significant differences were established in the training of a secondary school child in information security concepts. At the same time, during the training, the level of anxiety of schoolchildren while studying the aspects of information security in the subject area "Fundamentals of Spiritual and Moral Culture" was assessed, measurements were taken twice: before training and after training in the section "Network etiquette".

The data presented in table 6 indicates that prior to the experiment there are no statistically significant differences in the level of situational anxiety between the experimental and control groups.

At the end of the experiment, statistically significant differences were observed with a $1 \%$ significance level between the experimental and control groups. This is confirmed by the fact that $\chi 2 \mathrm{emp}=9.671731181$, more than $\chi 2 \mathrm{cr}=9.210$ for $1 \%$ significance level. This indicates that the level of situational anxiety among schoolchildren of the experimental group in the middle of information security training is increasing. Our observations show that an increase in anxiety is associated with the study of information threats by secondary school students and an analysis of their possible consequences, which is a natural reaction of the body adapting to new potential threats for it. After some time, the differences decreased and at the time of studying of another educational element related to information security, there were no statistically significant differences in the level of situational anxiety between the experimental and control groups. In any case, the high level of situational anxiety that has arisen requires the organizers of the educational process to take certain operational steps to reduce it, for example, switch to another type of activity or require the creation of previously prepared situations that dilute the stressful psychological situation.

The data presented in table 7 indicates that prior to the experiment there are no statistically significant differences in the level of personal anxiety between the experimental and control groups.

After completing the training, statistically significant differences in the level of personal anxiety of schoolchildren in the experimental and control groups before and after the experiment, as can be seen in Table 7, are not observed for the obtained $\chi 2 \mathrm{emp}=3.069255771$, since the obtained value is less than critical as $\chi 2 \mathrm{cr}=9.210$ as at $1 \%$, and at a $5 \%$ level, $\chi 2 \mathrm{cr}=5.991$ for two degrees of freedom. This may indicate that the study of educational elements related to information security issues does not increase the personal anxiety of secondary school students. 
The results of the study described in the article show that while studying the aspects of information security in a particular subject area, secondary school students meet the requirements of the modern stage of the development of the information society.

It has been established that the level of situational anxiety in the learning process can increase for a short time due to the natural reaction of the body, adapting to new potential threats for it. It is shown that the level of personal anxiety as the assimilation of new knowledge about information security is not critical.

Thus, the set goal of the research, which was to determine the influence of educational elements from a certain subject area related to information security guaranteeing on the level of anxiety of middle school students was achieved, a method for determining situational anxiety and personal anxiety was proposed for analyzing the psychological state of schoolchildren during the study of aspects of information security within the framework of the developed integrative model of teaching information security for students of secondary school age. The revealed patterns will allow to take into account the peculiarities of teaching information security issues to secondary school students and to organize this process more effectively.

\section{REFERENCES}

Abissova M., 2006. Servisy obucheniya informacionnoj bezopasnosti v teorii i metodike obucheniya informatike studentov gumanitarnyh i social'no-ekonomicheskih special'nostejRos. gos. ped. un-t im A.I. Gercena, SPb.

Bocharov M., 2019. Systematic information security training in elementary school, Atlantis Press, Vol. 105, pp 600-605.

Chou H. et al, 2017. The moderating roles of gender and social norms on the relationship between protection motivation and risky online behavior among in-service teachers, Computers \& Education, Vol. 112, pp 83-96.

Chou H. et al, 2016. Beyond identifying privacy issues in e-learning settings - Implications for instructional designers. Computers \& Education, Vol. 103, pp 253-265.

Dzhonson S., 2006. Kak zashchitit' detej ot opasnostej Interneta: virusov, programm-shpionov, spama, pornosajtov, vsplyvayushchih okon. NT Press, Moscow.

Fallon T. et al, 2018. Investigating social vulnerability in children using computer mediated role-play, Computers \& Education, Vol. 125, pp 458-464.

Gratian M. et al, 2018. Correlating human traits and cyber security behavior intentions, Computers \& Security, Vol. 73, pp 345-358.

Larsson K., 2017. Understanding and teaching critical thinking - A new approach, International Journal of Educational Research, Vol. 84, pp 32-42.

Lau W. et al, 2016. The relative importance of paternal and maternal parenting as predictors of adolescents' home Internet use and usage, Computers \& Education, Vol. 102, pp 224-233.

Partyka T., 2007. Informacionnaya bezopasnost': uchebnoe posobie dlya studentov uchrezhdenij srednego professional'nogo obrazovaniya. FORUM: INFRA-M, Moscow.

Plaza-de-la-Hoz J. et al, 2018. The family, key agent in youth empowerment in ICT society / La familia, agente clave de empoderamiento juvenil en la sociedad TIC, Cultura y Educación, Vol. 30, Issue 2, pp 338-367.

Poos J. et al, 2017. Battling bias: Effects of training and training context, Computers \& Education, Vol. 111, pp 101-113.

Rooney P., 2018. A cultural assets model for school effectiveness, Cambridge Journal of Education, Vol. 48, Issue 4, pp 445-459.

Thompson N. et al, 2017. «Security begins at home»: Determinants of home computer and mobile device security behavior, Computers \& Security, Vol. 70, pp 376-391.

Usova A., 1986. Formirovanie u shkol'nikov nauchnyh ponyatij v processe obucheniya. Pedagogika, Moscow, pp. 115-120.

Yhomee S. et al, 2012. Computer use and stress, sleep disturbances, and symptoms of depression among young adults - a prospective cohort study, BMC Psychiatry, - Vol. 12, Issue 176, pp 1-14. 